\title{
Canonical correlation analysis of hydrological response and soil erosion under moving rainfall*
}

\author{
Qi-hua RAN, Zhi-nan SHI, Yue-ping XU ${ }^{\dagger *}$ \\ (Institute of Hydrology and Water Resources, Zhejiang University, Hangzhou 310058, China) \\ ${ }^{\dagger}$ E-mail: yuepingxu@zju.edu.cn \\ Received Nov. 16, 2012; Revision accepted Mar. 11, 2013; Crosschecked Apr. 19, 2013
}

\begin{abstract}
The impacts of rainfall direction on the degree of hydrological response to rainfall properties were investigated using comparative rainfall-runoff experiments on a small-scale slope $(4 \mathrm{~m} \times 1 \mathrm{~m})$, as well as canonical correlation analysis (CCA). The results of the CCA, based on the observed data showed that, under conditions of both upstream and downstream rainfall movements, the hydrological process can be divided into instantaneous and cumulative responses, for which the driving forces are rainfall intensity and total rainfall, and coupling with splash erosion and wash erosion, respectively. The response of peak runoff $\left(P_{\mathrm{r}}\right)$ to intensity-dominated rainfall action appeared to be the most significant, and also runoff $(R)$ to rainfall-dominated action, both for upstream- and downstream-moving conditions. Furthermore, the responses of sediment erosion in downstream-moving condition were more significant than those in upstream-moving condition. This study indicated that a CCA between rainfall and hydrological characteristics is effective for further exploring the rainfall-runoff-erosion mechanism under conditions of moving rainfall, especially for the downstream movement condition.
\end{abstract}

Key words: Moving rainfall, Runoff, Sediment erosion, Canonical correlation analysis (CCA) doi: $10.1631 /$ jzus.A1200306

\section{Introduction}

Rainfall-runoff processes, together with the related upland erosion and sediment transport, are highly complex, and are impacted by two main aspects: rainfall and watershed characteristics (Yen and Chow, 1969; Singh, 2002; de Lima and Singh, 2003; Nunes et al., 2006; de Lima et al., 2009; Ran et al., 2012a; 2012b; Seo et al., 2012). Watershed characteristics usually include topography, shape, slope, drainage pattern, etc. (Montgomery and Dietrich, 2002; Assouline and Ben-Hur, 2006; Ran et al., 2009; Seo and Schmidt, 2012). Rainfall characteristics, including rainfall intensity, duration, direction, and velocity of movement, are more variable, in spatial

\footnotetext{
${ }^{\ddagger}$ Corresponding author

* Project supported by the National Basic Research Program (973) of China (No. 2011CB409901-01), and the National Natural Science Foundation of China (No. 4081011)

(C) Zhejiang University and Springer-Verlag Berlin Heidelberg 2013
}

and temporal contexts, and often impact both the integrated response (e.g., runoff hydrograph) (de Lima et al., 2009; Seo et al., 2012) and the distributed response (e.g., the temporal and spatial variability of soil moisture) (Ran et al., 2009; 2012a).

As characteristics of natural rainfall, directions of rainfall movement and velocity have an important influence on the runoff response and soil loss (Seo and Schmidt, 2012). Singh (2002) pointed out that the rainfall movement velocity has a significant influence on the surface/near-surface hydrologic response and soil erosion, especially for extreme storms. Storms that move rapidly have much less impact on peak discharge than those moving at an equal speed. Yen and Chow (1968) showed that a lower velocity causes a larger peak discharge, and less time reaches peak. While given the impacts by soil properties, runoff is also generated as a result of crust development on the soil surface during or after precipitation (Ran et al., 2012b). Crusts always affect runoff generation by 
decreasing surface $K_{\mathrm{s}}$ and subsequently also water infiltration (Carmi and Berliner, 2008). Previous studies have shown that ignoring storm movement can result in considerable overestimation and underestimation of runoff peaks (de Lima and Singh, 2003; Seo and Schmidt., 2012). de Lima et al. (2009) simulated storms crossing in different directions, and showed that soil loss resulting from rainstorms moving in different directions were clearly linked to the characteristics of the corresponding overland flow hydrographs and peak discharge. Seo and Schmidt (2012) also studied the relations among the direction of rainfall movement, the maximum peak discharge, and the network configuration. However, still few studies have revealed the impacts of rainfall movement directions on the characteristics of different runoff and erosion development stages, coupled with the crust development properties during those periods.

The influences of rainfall characteristics on hydrologic responses have been investigated experimentally (de Lima et al., 2009; Ran et al., 2011; 2012b; 2012c; He et al., 2013), using field investigations (Ran et al., 2011), and through computational modeling (Singh, 2005; Nunes et al., 2006; Ran et al., 2009). Olson and Wischmeier (1963) measured the soil loss per unit of rainfall erosivity based on simulated rainfall and plot experiments, and then scientists led by Wischmeier developed the famous universal soil loss equation (USLE), in which rainfall was considered a major influencing factor impacting overflow (Foster et al., 1977; Wischmeier and Smith, 1978). Since then, quantitative studies of the effects of rainfall characteristics on soil erosion have been conducted (Nunes et al., 2006; Ran et al., 2012a; 2012b). Dessu and Melesse (2012) recently found that the soil and water assessment tool (SWAT) has the potential to simulate the long-term rainfall runoff process. Meanwhile, some scholars have begun to further discuss the mechanisms of hydrological response using statistical methods (e.g., SPSS), again in order to systematically study the relationships between the response factors (Rice, 1972; Arthur et al., 2011; Pappas et al., 2011), while still remaining at the macro level, and cannot reveal the detail internal correlations between rainfall and slope response properties. Furthermore, directions of rainfall movement are always ignored in those statistical methods.
The objective of this study is to discuss the canonical correlation between sets of rainfall characteristics and hydrological response characteristics by systematic statistical methods, and to compare the response degree under different directions of rainfall movement along a small-scale slope.

\section{Materials and methods}

\subsection{Laboratory experiments}

The experiments carried out in this study involved the use of a rainfall simulator, a tilted soil flume, a runoff recording system, and a set of soil water content monitoring devices, set up as shown in Fig. 1. Multiple scenarios relating to various rainfall movement directions, intensities $\left(I_{\mathrm{r}}\right)$ and event durations $\left(D_{\mathrm{r}}\right)$ were considered. Details of the experimental facilities (e.g., rainfall simulator, soil flume, and gathering devices) as well as the initial treatment of the soil can be found in descriptions in our previous study (Ran et al., 2012b).

The rainfall scenarios used in this study were constructed by varying four parameters: direction of rainfall movement, rainfall intensity $\left(I_{\mathrm{r}}\right)$, duration $\left(D_{\mathrm{r}}\right)$, and the interval between rainfall events. To simplify the laboratory experiments, only two directions were considered for rainfall movement: upstream and downstream, with rainfall moving in only one direction during each event. Three combinations of $I_{\mathrm{r}}$ and $D_{\mathrm{r}}$ were considered: low $I_{\mathrm{r}}\left(1 \times 10^{-5} \mathrm{~m} / \mathrm{s}\right)$ with long $D_{\mathrm{r}}$ (120-240 min), moderate $I_{\mathrm{r}}\left(2.5 \times 10^{-5} \mathrm{~m} / \mathrm{s}\right)$ with medium $D_{\mathrm{r}}(60-120 \mathrm{~min})$, and extreme $I_{\mathrm{r}}\left(4 \times 10^{-5} \mathrm{~m} / \mathrm{s}\right)$ with short $D_{\mathrm{r}}(15-60 \mathrm{~min})$. The raindrop generator was moved upstream or downstream by $0.2 \mathrm{~m}$ at regular time intervals for each moving rainfall scenario. The equivalent velocity for this movement ranged from $0.2 \times 10^{-3} \mathrm{~m} / \mathrm{s}$ to $4.3 \times 10^{-3} \mathrm{~m} / \mathrm{s}$. Details for setting, as well as the data used in the experiments were described in our previous study (Ran et al., 2012b).

\subsection{Canonical correlation analysis (CCA)}

Canonical correlation analysis (CCA), a method for studying the correlativity between two different sets of variables, is aimed to identify and quantify their internal relationship. The brief mathematical principles of CCA are presented as follows (Wang et al., 2012). 
(a)

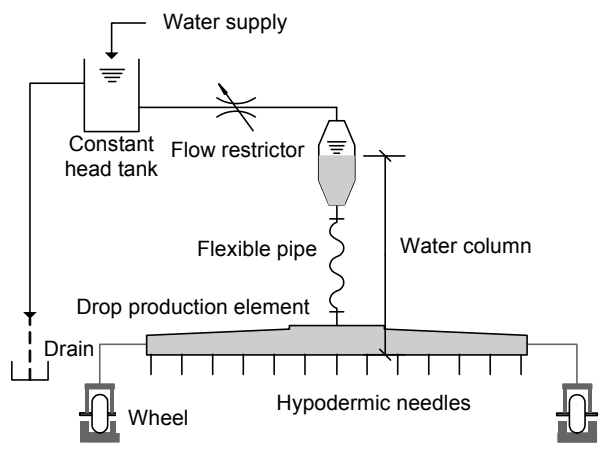

(b)

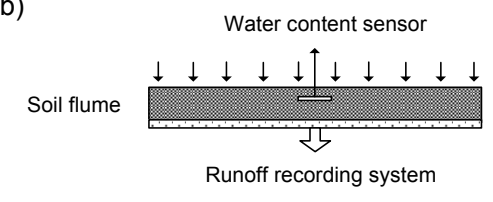

(c)

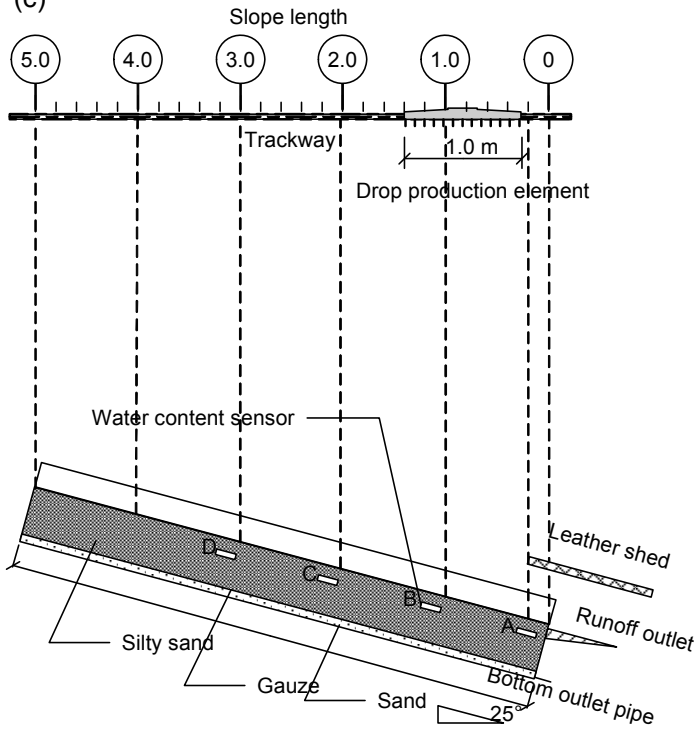

Fig. 1 Schematic representation of the laboratory experimental set-up used in this study

(a) Section drawing of the experimental set-up; (b) Section drawing of the soil flume at the outlet; (c) Elevation drawing of the experimental set-up (unit: $\mathrm{m}$ )

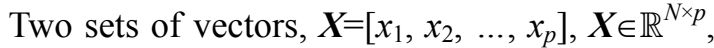
and $\boldsymbol{Y}=\left[y_{1}, y_{2}, \ldots, y_{q}\right], \boldsymbol{Y} \in \mathbb{R}^{N \times q}$, and their linear combinations $\boldsymbol{U}=\boldsymbol{a}^{\mathrm{T}} \boldsymbol{X}$ and $\boldsymbol{V}=\boldsymbol{b}^{\mathrm{T}} \boldsymbol{Y}$, were used to study the correlativity between the primitive variables $\boldsymbol{X}$ and $\boldsymbol{Y}$.

CCA seeks a pair of vectors, $\boldsymbol{a}$ and $\boldsymbol{b}$, which maximize the correlation $\rho(\boldsymbol{U}, \boldsymbol{V})$,

$\rho(\boldsymbol{U}, \boldsymbol{V})=\frac{\operatorname{Cov}(\boldsymbol{U}, \boldsymbol{V})}{\sqrt{\operatorname{Var}(\boldsymbol{U})} \sqrt{\operatorname{Var}(\boldsymbol{V})}}=\frac{\boldsymbol{a}^{\mathrm{T}} \sum_{12} \boldsymbol{b}}{\sqrt{\boldsymbol{a}^{\mathrm{T}} \sum_{11} \boldsymbol{a}} \sqrt{\boldsymbol{b}^{\mathrm{T}} \sum_{22} \boldsymbol{b}}}$, where $\Sigma_{12}$ is a sample covariance matrix between $\boldsymbol{X}$ and $\boldsymbol{Y}, \Sigma_{21}$ between $\boldsymbol{Y}$ and $\boldsymbol{X}$, and $\Sigma_{12}=\Sigma_{21}^{\mathrm{T}} ; \boldsymbol{\Sigma}_{11}$ and $\Sigma_{22}$ are the covariance matrices of $\boldsymbol{X}$ and $\boldsymbol{Y}$, respectively.

The correlation coefficients of these random variables do not change if they are multiplied by a constant; some constraints (Eq. (2)) are included in Eq. (1) in order to prevent unnecessary repetition:

$$
\operatorname{Var}(\boldsymbol{U})=\boldsymbol{a}^{\mathrm{T}} \sum_{11} \boldsymbol{a}=1, \operatorname{Var}(\boldsymbol{V})=\boldsymbol{b}^{\mathrm{T}} \sum_{11} \boldsymbol{b}=1 .
$$

Setting $\boldsymbol{A}=\sum_{11}^{-1} \Sigma_{12} \Sigma_{22}^{-1} \Sigma_{21}$ and $\boldsymbol{B}=\sum_{22}^{-1} \Sigma_{21} \sum_{11}^{-1} \Sigma_{12}$, the solution of Eq. (1) can be obtained by solving either of the following two eigenvalue problems:

$$
\boldsymbol{A a}=\lambda^{2} \boldsymbol{a}, \boldsymbol{B} \boldsymbol{b}=\lambda^{2} \boldsymbol{b},
$$

where the square roots of the eigenvalues $\lambda^{2}$, obtained from Eq. (3), are called canonical correlations, and the vectors $\boldsymbol{a}$ and $\boldsymbol{b}$ are the eigenvectors corresponding to $\boldsymbol{A}$ and $\boldsymbol{B}$, respectively. Consequently, we acquire the $i$ th set of canonical variables:

$$
\boldsymbol{U}_{i}=\boldsymbol{a}^{(i)^{\mathrm{T}}} \boldsymbol{X}, \boldsymbol{V}_{i}=\boldsymbol{b}^{(i)^{\mathrm{T}}} \boldsymbol{Y}, \quad i=1,2, \ldots, p,
$$

as well as the $i$ th canonical correlation coefficient $\lambda$.

\section{Results}

In this study, a total of 65 1-d laboratory experiments, comprising 33 upstream-moving and 32 downstream-moving rainfall events, were carried out in $23 \mathrm{~d}$. Table 1 summarizes the results obtained from the physical experiments. Table 1 includes two sets of information from the experiment data: rainfall and slope response (runoff, erosion). Therefore, two sets of primitive variables for the CCA are presented as follows:

1. Primitive variables of rainfall characteristics:

$$
\boldsymbol{X}=\left(D_{\mathrm{r}}, I_{\mathrm{r}}, Q\right)^{\mathrm{T}},
$$

where $Q$ is the total rainfall for each experiment.

2. Primitive variables of hydrological response characteristics: 
Table 1 Experimental observed results in the study for upstream- and downstream-moving conditions, respectively

\begin{tabular}{|c|c|c|c|c|c|c|c|c|}
\hline $\begin{array}{c}\text { Serial } \\
\text { number }\end{array}$ & Test date & $\begin{array}{c}\text { Test } \\
\text { number }\end{array}$ & $\begin{array}{c}\text { No-rain } \\
\text { interval (s) }\end{array}$ & $\begin{array}{c}P_{\mathrm{r}} \\
\left(\times 10^{-6} \mathrm{~m}^{3} / \mathrm{s}\right) \\
\end{array}$ & $\begin{array}{c}R \\
\left(\times 10^{-6} \mathrm{~m}^{3}\right) \\
\end{array}$ & $\begin{array}{c}C_{\mathrm{s}} \\
(\mathrm{g} / \mathrm{L}) \\
\end{array}$ & $\begin{array}{c}P_{\mathrm{s}} \\
(\mathrm{g} / \mathrm{s}) \\
\end{array}$ & $\begin{array}{c}S \\
(\mathrm{~g})\end{array}$ \\
\hline \multicolumn{9}{|c|}{ Upstream-moving } \\
\hline 1 & 08-13 & US001 & & 30.2 & 22088 & 57.1392 & 2.1800 & 1262.0902 \\
\hline 2 & & US002 & 850 & 38.8 & 31002 & 30.5435 & 1.5950 & 946.9093 \\
\hline 3 & & US003 & 1750 & 40.0 & 31898 & 20.0078 & 1.0200 & 638.2087 \\
\hline 4 & & US004 & 3550 & 38.9 & 31953 & 14.6201 & 0.7330 & 467.1559 \\
\hline 5 & & US005 & 12250 & 40.8 & 31635 & 10.8623 & 0.6140 & 343.6231 \\
\hline 6 & $06-27$ & US006 & & 24.3 & 36147 & 57.4379 & 1.4795 & 2076.1852 \\
\hline 7 & & US007 & 1700 & 28.8 & 45929 & 31.7919 & 1.0000 & 1460.1692 \\
\hline 8 & & US008 & 3500 & 27.5 & 44425 & 19.4827 & 0.6505 & 865.5200 \\
\hline 9 & & US009 & 10700 & 23.8 & 38085 & 12.4460 & 0.4505 & 474.0071 \\
\hline 10 & $08-21$ & US010 & & 44.1 & 137000 & 19.9227 & 0.9440 & 2729.4038 \\
\hline 11 & & US011 & 3400 & 49.6 & 159500 & 8.8707 & 0.5475 & 1414.8714 \\
\hline 12 & & US012 & 11500 & 48.5 & 159300 & 6.2134 & 0.3585 & 989.7924 \\
\hline 13 & $07-27$ & US013 & & 43.3 & 274680 & 30.2731 & 1.2753 & 8315.4166 \\
\hline 14 & & US014 & 14000 & 45.0 & 283553 & 15.8695 & 0.7437 & 4499.8510 \\
\hline 15 & & UM001 & 3380 & 13.6 & 16780 & 69.2465 & 0.9965 & 1161.9565 \\
\hline 16 & & UM002 & 1700 & 22.0 & 34124 & 36.8433 & 0.9275 & 1257.2402 \\
\hline 17 & $07-25$ & UM003 & & 22.4 & 35071 & 24.2902 & 0.7085 & 851.8823 \\
\hline 18 & & UM004 & 12500 & 21.5 & 34635 & 16.9290 & 0.5005 & 586.3376 \\
\hline 19 & $06-25$ & UM005 & & 14.3 & 40698 & 29.0862 & 0.5013 & 1183.7500 \\
\hline 20 & & UM006 & 22200 & 15.3 & 46202 & 18.1655 & 0.3777 & 839.2833 \\
\hline 21 & $07-03$ & UM008 & & 22.0 & 139270 & 36.9969 & 0.8758 & 5152.5629 \\
\hline 22 & & UM009 & 11300 & 21.3 & 137850 & 14.9373 & 0.3293 & 2059.1092 \\
\hline 23 & 08-04 & UM010 & & 26.0 & 239279 & 32.6173 & 0.9820 & 7804.6448 \\
\hline 24 & & UM011 & 9000 & 27.3 & 268464 & 22.7816 & 0.7195 & 6116.0404 \\
\hline 25 & $06-21$ & UW001 & & 0.0 & 0 & 0.0000 & 0.0000 & 0.0000 \\
\hline 26 & & UW002 & 3400 & 0.2 & 154 & 4.6753 & 0.0013 & 0.7200 \\
\hline 27 & & UW003 & 14200 & 7.5 & 18446 & 6.7196 & 0.0686 & 123.9500 \\
\hline 28 & $06-15$ & UW004 & & 0.0 & 0 & 0.0000 & 0.0000 & 0.0000 \\
\hline 29 & & UW005 & 8700 & 4.2 & 12571 & 10.6913 & 0.0513 & 134.4000 \\
\hline 30 & 08-08 & UW006 & & 9.5 & 87500 & 39.3379 & 0.4008 & 3442.0670 \\
\hline 31 & & UW007 & 9900 & 10.0 & 95500 & 24.9994 & 0.3022 & 2387.4386 \\
\hline 32 & $08-17$ & UW008 & & 10.8 & 130644 & 41.0484 & 0.4652 & 5362.7320 \\
\hline 33 & & UW009 & 7700 & 10.8 & 138506 & 23.6539 & 0.2995 & 3276.2119 \\
\hline \multicolumn{9}{|c|}{ Downstream-moving } \\
\hline 34 & 08-15 & DS001 & & 29.0 & 13643 & 79.5117 & 2.1290 & 1084.7785 \\
\hline 35 & & DS002 & 850 & 38.9 & 27896 & 34.5689 & 1.4430 & 964.3332 \\
\hline 36 & & DS003 & 1750 & 47.3 & 29921 & 21.8798 & 1.1060 & 654.6669 \\
\hline 37 & & DS004 & 3550 & 41.5 & 30100 & 15.9385 & 0.8010 & 479.7477 \\
\hline 38 & & DS005 & 11650 & 43.0 & 30726 & 10.5380 & 0.5440 & 323.7915 \\
\hline 39 & $06-29$ & DS006 & & 24.1 & 21109 & 40.9603 & 1.1595 & 864.6310 \\
\hline 40 & & DS007 & 1900 & 27.3 & 41261 & 19.5182 & 0.6170 & 805.3391 \\
\hline 41 & & DS008 & 4100 & 27.5 & 41576 & 12.2782 & 0.4150 & 510.4771 \\
\hline 42 & & DS009 & 3500 & 27.8 & 40082 & 8.3786 & 0.2995 & 335.8327 \\
\hline 43 & 08-02 & DS010 & & 39.9 & 92813 & 49.4416 & 1.9830 & 4588.8208 \\
\hline 44 & & DS011 & 3400 & 43.6 & 133924 & 21.3428 & 1.1515 & 2858.3078 \\
\hline 45 & & DS012 & 10600 & 42.3 & 131230 & 17.1447 & 1.0670 & 2249.9005 \\
\hline 46 & $07-29$ & DS013 & & 31.9 & 157332 & 43.0180 & 1.3260 & 6768.1027 \\
\hline 47 & & DS014 & 13880 & 33.2 & 203942 & 20.9780 & 0.9073 & 4278.2919 \\
\hline
\end{tabular}




\begin{tabular}{|c|c|c|c|c|c|c|c|c|}
\hline 48 & $07-01$ & DM001 & & 21.8 & 21757 & 59.2334 & 1.3275 & 1288.7402 \\
\hline 49 & & DM002 & 1700 & 24.7 & 37425 & 25.4327 & 0.7715 & 951.8205 \\
\hline 50 & & DM003 & 3500 & 24.5 & 37426 & 15.6115 & 0.4910 & 584.2754 \\
\hline 51 & & DM004 & 11900 & 23.3 & 34848 & 10.2470 & 0.3325 & 357.0881 \\
\hline 52 & $07-21$ & DM005 & & 20.1 & 34180 & 64.7911 & 1.4627 & 2214.5606 \\
\hline 53 & & DM006 & 3600 & 20.2 & 62027 & 31.8704 & 0.8443 & 1976.8254 \\
\hline 54 & & DM007 & 11800 & 19.7 & 60074 & 20.9033 & 0.5263 & 1255.7441 \\
\hline 55 & $07-05$ & DM008 & & 21.2 & 77472 & 29.2863 & 0.7062 & 2268.8703 \\
\hline 56 & & DM009 & 11900 & 21.8 & 132089 & 14.2250 & 0.4022 & 1878.9665 \\
\hline 57 & 08-06 & DM010 & & 22.3 & 152310 & 27.7122 & 0.6617 & 4220.8460 \\
\hline 58 & & DM011 & 9000 & 23.6 & 172201 & 21.0547 & 0.5575 & 3625.6409 \\
\hline 59 & $06-23$ & DW001 & & 1.1 & 730 & 14.0137 & 0.0176 & 10.2300 \\
\hline 60 & & DW002 & 16000 & 5.5 & 11589 & 21.0640 & 0.1808 & 244.1000 \\
\hline 61 & & DW003 & 3390 & 6.1 & 14552 & 16.2507 & 0.1475 & 236.4800 \\
\hline 62 & $08-10$ & DW006 & & 10.9 & 55166 & 40.9443 & 0.4577 & 2258.7356 \\
\hline 63 & & DW007 & 10020 & 11.2 & 103494 & 24.0305 & 0.3160 & 2487.0143 \\
\hline 64 & 08-19 & DW008 & & 9.9 & 51286 & & 0.3720 & 1710.2001 \\
\hline 65 & & DW009 & 9060 & 10.4 & 100958 & & 0.2872 & 2475.9238 \\
\hline
\end{tabular}

$$
\boldsymbol{Y}=\left(P_{\mathrm{r}}, R, C_{\mathrm{s}}, P_{\mathrm{s}}, S\right)^{\mathrm{T}},
$$

where $P_{\mathrm{r}}$ is the peak runoff, $R$ the total runoff, $C_{\mathrm{s}}$ the sediment concentration, $P_{\mathrm{s}}$ the peak sediment discharge, and $S$ the total sediment discharge at the outlet of the soil slope for each rainfall experiment.

The CCAs were conducted using SPSS based on the observed data (Table 1); the results showed that two sets of canonical relationships (I, II) between rainfall characteristics and response characteristics were obtained, for both conditions (Tables 2-6), these being: set I (CVU I) and set II (CVU II), canonical variables of the upstream movement condition; and set I (CVD I) and set II (CVD II), canonical variables of the downstream movement condition. Eqs. (5)-(8) represent the canonical conversion relations between the primitive and canonical variables. Figs. $2 \mathrm{a}-2 \mathrm{~d}$ present the canonical loading relationships corresponding to Eqs. (5)-(8), respectively.

$$
\begin{aligned}
& \left\{\begin{array}{l}
\boldsymbol{U}_{\mathrm{u} 1}=-0.038 D_{\mathrm{r}}-0.631 I_{\mathrm{r}}+1.021 Q, \\
\boldsymbol{V}_{\mathrm{u} 1}=-0.613 P_{\mathrm{r}}+0.937 R+0.005 C_{\mathrm{s}}-0.116 P_{\mathrm{s}}+0.144 S,
\end{array}\right. \\
& \left\{\begin{array}{l}
\boldsymbol{U}_{\mathrm{u} 2}=0.045 D_{\mathrm{r}}+0.881 I_{\mathrm{r}}+0.297 Q, \\
\boldsymbol{V}_{\mathrm{u} 2}=0.774 P_{\mathrm{r}}+0.326 R+0.009 C_{\mathrm{s}}+0.112 P_{\mathrm{s}}-0.061 S,
\end{array}\right. \\
& \left\{\begin{array}{l}
\boldsymbol{U}_{\mathrm{d} 1}=0.149 D_{\mathrm{r}}+1.055 I_{\mathrm{r}}-0.363 Q, \\
\boldsymbol{V}_{\mathrm{d} 1}=0.788 P_{\mathrm{r}}-0.080 R-0.095 C_{\mathrm{s}}+0.369 P_{\mathrm{s}}-0.203 S,
\end{array}\right.
\end{aligned}
$$

$$
\left\{\begin{array}{l}
\boldsymbol{U}_{\mathrm{d} 2}=-0.171 D_{\mathrm{r}}+0.125 I_{\mathrm{r}}+1.100 Q, \\
\boldsymbol{V}_{\mathrm{d} 2}=0.249 P_{\mathrm{r}}+0.691 R+0.306 C_{\mathrm{s}}-0.348 P_{\mathrm{s}}+0.345 S .
\end{array}\right.
$$

Generally, the canonical correlation coefficient is close to 1 (not less than 0.96) for all pairs of canonical variables (Tables 2-5), clearly indicating a strong correlation between rainfall characteristics and hydrologic response characteristics.

\subsection{Analysis of CVU I, CVU II, CVD I and CVD II}

For CVU I (Table 2, Eq. (5), Fig. 2a (p.359) ), the conversion coefficient of $Q(1.021)$ in $U_{\mathrm{u} 1}$ is much larger than that of $D_{\mathrm{r}}(-0.038)$ and $I_{\mathrm{r}}(-0.631)$, which means $\boldsymbol{U}_{\mathrm{u} 1}$ mainly represents the properties of total rainfall. Here, $D_{\mathrm{r}}$ is perceived as a rectified variable, the reason is that its canonical conversion coefficient $(-0.038)$ and canonical correlation coefficient $(0.881)$ are opposite in sign, as is $C_{\mathrm{s}}$ in $\boldsymbol{V}_{\mathrm{u} 1}$. Similarly, $D_{\mathrm{r}}$ and $S$ in Eq. (6), $D_{\mathrm{r}}$ and $C_{\mathrm{s}}$ in Eq. (7), as well as $D_{\mathrm{r}}$ and $P_{\mathrm{s}}$ in Eq. (8) are all rectified variables for the same reason. The opposite canonical variable $\boldsymbol{V}_{\mathrm{u} 1}$ mainly represents the property of $R$, for its largest canonical conversion coefficient (0.937), and the absolute of the coefficient for $P_{\mathrm{r}}$ is a little smaller than that of $R$, while they are opposite in sign. Generally, the degree of response of sediment erosion is weaker than runoff processes for the relatively small canonical conversion coefficients of $P_{\mathrm{s}}$ and $S$, so it is included with the canonical loading diagram (Fig. 2a). 
For CVU II (Table 3, Eq. (6), Fig. 2b), it is apparent that the canonical conversion coefficient of $I_{\mathrm{r}}$ is the largest in the conversion relationship with $\boldsymbol{U}_{\mathrm{u} 2}$, which means that the whole rainfall properties appear to be more significant as $I_{\mathrm{r}}$ increases, and the coefficient of $Q$ is much smaller than that of $I_{\mathrm{r}}$. The opposite $V_{\mathrm{u} 2}$, is mainly embodied by the characteristics of $P_{\mathrm{r}}$, of which the canonical conversion coefficient is the largest (0.774), and that of $R$ the second largest (0.326) In general, the responses of $C_{\mathrm{s}}$ and $P_{\mathrm{s}}$ are much weaker than both $P_{\mathrm{r}}$ and $R$ in terms of their relatively small canonical coefficients. Thus, it can be seen that CVU II represents the main response characteristics of $P_{\mathrm{r}}$ under a rainfall force dominated by $I_{\mathrm{r}}$, and also some of the weaker responses of soil erosion, so it is included with the canonical loading diagram (Fig. 2b).

As for CVD I (Table 4, Eq. (7), Fig. 2c), similar to CVU II, the absolute canonical conversion coefficient for the $\boldsymbol{U}_{\mathrm{d} 1}$ of $I_{\mathrm{r}}(1.055)$ is much larger than that for $Q(0.363) . P_{\mathrm{r}}$ also has the largest effect on $\boldsymbol{V}_{\mathrm{d} 1}$ as it has the largest canonical coefficient $(0.788)$, and $P_{\mathrm{s}}$ is the second largest (0.369), while those of $R$ and $S$ are clearly much weaker. Thus, CVD I mainly shows the $P_{\mathrm{r}}$-dominated response under $I_{\mathrm{r}}$-based rainfall action, coupled with the relatively weak response of $P_{\mathrm{s}}$, so it is included with the canonical loading diagram (Fig. 2c).

Table 2 Canonical correlation analysis result for CVU I

\begin{tabular}{|c|c|c|c|c|}
\hline $\begin{array}{c}\mathrm{CVU} \\
\mathrm{I}\end{array}$ & Variable & $\begin{array}{c}\text { Standard canonical } \\
\text { coefficient }\end{array}$ & $\begin{array}{c}\text { Canonical } \\
\text { loadings }\end{array}$ & $\begin{array}{c}\text { Cross } \\
\text { loadings }\end{array}$ \\
\hline \multirow{3}{*}{$\boldsymbol{U}_{\mathrm{u} 1}$} & $D_{\mathrm{r}}$ & -0.038 & 0.881 & 0.878 \\
\hline & $I_{\mathrm{r}}$ & -0.631 & -0.320 & -0.319 \\
\hline & $Q$ & 1.021 & 0.815 & 0.812 \\
\hline \multirow{5}{*}{$\boldsymbol{V}_{\mathrm{u} 1}$} & $P_{\mathrm{r}}$ & -0.613 & -0.219 & -0.218 \\
\hline & $R$ & 0.937 & 0.767 & 0.765 \\
\hline & $C_{\mathrm{s}}$ & 0.005 & -0.018 & -0.018 \\
\hline & $P_{\mathrm{s}}$ & -0.116 & -0.291 & -0.290 \\
\hline & $S$ & 0.144 & 0.789 & 0.786 \\
\hline
\end{tabular}

Canonical correlation between $\boldsymbol{U}_{\mathrm{u} 1}$ and $\boldsymbol{V}_{\mathrm{u} 1}: 0.997$

Table 4 Canonical correlation analysis result for CVD I

\begin{tabular}{cccrr}
\hline $\begin{array}{c}\text { CVD } \\
\text { I }\end{array}$ & Variable & $\begin{array}{c}\text { Standard canonical } \\
\text { coefficient }\end{array}$ & $\begin{array}{c}\text { Canonical } \\
\text { loadings }\end{array}$ & $\begin{array}{c}\text { Cross } \\
\text { loadings }\end{array}$ \\
\hline \multirow{3}{*}{$\boldsymbol{U}_{\mathrm{d} 1}$} & $D_{\mathrm{r}}$ & 0.149 & -0.652 & -0.644 \\
& $I_{\mathrm{r}}$ & 1.055 & 0.967 & 0.956 \\
& $Q$ & -0.363 & -0.211 & -0.209 \\
\hline \multirow{6}{*}{$V_{\mathrm{d} 1}$} & $P_{\mathrm{r}}$ & 0.788 & 0.954 & 0.943 \\
& $R$ & -0.080 & -0.043 & -0.043 \\
& $C_{\mathrm{s}}$ & -0.095 & 0.128 & 0.127 \\
& $P_{\mathrm{s}}$ & 0.369 & 0.679 & 0.671 \\
& $S$ & -0.203 & -0.030 & -0.030 \\
\hline
\end{tabular}

Canonical correlation between $\boldsymbol{U}_{\mathrm{d} 1}$ and $\boldsymbol{V}_{\mathrm{d} 1}: 0.988$
Moreover, like CVU I, CVD II (Table 5, Eq. (8), Fig. 2d) mainly shows an $R$-dominated response under the main force of $Q$, while the responses of $P_{\mathrm{r}}, C_{\mathrm{s}}$ and $S$ respond to a similar degree.

\subsection{Redundancy analysis}

Table 6 shows the redundancy analysis results, presenting the reference value of the CCA. When rainfall moves upstream, the degree of explanation of $\boldsymbol{X}$ - the primitive variable for rainfall properties - given by the canonical variable $\boldsymbol{U}_{\mathrm{ul}}$, is $51.4 \%$ (CVX1-1), and for $\boldsymbol{U}_{\mathrm{u} 2} 41.8 \%$ (CVX1-2), $\quad \boldsymbol{V}_{\mathrm{u} 1}$ (CVX2-1) 51.1\%, and $\boldsymbol{V}_{\mathrm{u} 2} 40.8 \%$ (CVX2-2). However, the effect of rainfall on slope response is singledirectional and their opposite canonical variables $\boldsymbol{U}_{\mathrm{u} 1}$ 26.7\% (CVY2-1), and $\boldsymbol{U}_{\mathrm{u} 2} 36.4 \%$ (CVY2-2). When rainfall moves downstream, the degree of explanation of $\boldsymbol{X}$ given by $\boldsymbol{U}_{\mathrm{d} 1}$ and $\boldsymbol{U}_{\mathrm{d} 2}$ is $46.9 \%(\mathrm{CV} X 1-1)$ and $45.7 \%$ (CV $X 1-2)$, respectively, also that of $\boldsymbol{Y}$ given by $\boldsymbol{V}_{\mathrm{d} 1}$ and $\boldsymbol{V}_{\mathrm{d} 2}$ is $27.8 \%(\mathrm{CV} Y 1-1)$ and $38.2 \%$ (CVY1-2), respectively, and $\boldsymbol{U}_{\mathrm{d} 1} 27.2 \%(\mathrm{CV} Y 2-1), \boldsymbol{U}_{\mathrm{d} 2} 35.9 \%$ (CVY2-2).

Thus, it is acceptable for the explanation degree of primitive rainfall property variables given by $\boldsymbol{U}_{\mathrm{u} 1}$ and $\boldsymbol{U}_{\mathrm{u} 2}$ for upstream-movement conditions; although it is a little poorer for that of $\boldsymbol{Y}$, because the ideal state

Table 3 Canonical correlation analysis result for CVU II

\begin{tabular}{ccccc}
\hline $\begin{array}{c}\text { CVU } \\
\text { II }\end{array}$ & Variable & $\begin{array}{c}\text { Standard canonical } \\
\text { coefficient }\end{array}$ & $\begin{array}{c}\text { Canonical } \\
\text { loadings }\end{array}$ & $\begin{array}{c}\text { Cross } \\
\text { loadings }\end{array}$ \\
\hline \multirow{4}{*}{$\boldsymbol{U}_{\mathrm{u} 2}$} & $D_{\mathrm{r}}$ & 0.045 & -0.145 & -0.143 \\
& $I_{\mathrm{r}}$ & 0.881 & 0.947 & 0.936 \\
& $Q$ & 0.297 & 0.580 & 0.573 \\
\hline \multirow{6}{*}{$\boldsymbol{V}_{\mathrm{u} 2}$} & $P_{\mathrm{r}}$ & 0.774 & 0.971 & 0.960 \\
& $R$ & 0.326 & 0.641 & 0.633 \\
& $C_{\mathrm{s}}$ & 0.009 & 0.095 & 0.094 \\
& $P_{\mathrm{s}}$ & 0.112 & 0.568 & 0.561 \\
\multicolumn{7}{c}{ Canonical correlation between $\boldsymbol{U}_{\mathrm{b}}$ and $\boldsymbol{V}_{2} \cdot 0.988$}
\end{tabular}

Table 5 Canonical correlation analysis result for CVD II

\begin{tabular}{ccccc}
\hline $\begin{array}{c}\text { CVD } \\
\text { II }\end{array}$ & Variable & $\begin{array}{c}\text { Standard canonical } \\
\text { coefficient }\end{array}$ & $\begin{array}{c}\text { Canonical } \\
\text { loadings }\end{array}$ & $\begin{array}{c}\text { Cross } \\
\text { loadings }\end{array}$ \\
\hline \multirow{4}{*}{$\boldsymbol{U}_{\mathrm{u} 2}$} & $D_{\mathrm{r}}$ & -0.171 & 0.600 & 0.582 \\
& $I_{\mathrm{r}}$ & 0.125 & 0.250 & 0.242 \\
& $Q$ & 1.100 & 0.974 & 0.944 \\
\hline \multirow{6}{*}{$\boldsymbol{V}_{\mathrm{u} 2}$} & $P_{r}$ & 0.249 & 0.248 & 0.240 \\
& $R$ & 0.691 & 0.973 & 0.943 \\
& $C_{\mathrm{s}}$ & 0.306 & 0.063 & 0.061 \\
& $P_{\mathrm{s}}$ & -0.348 & 0.208 & 0.207 \\
& $S$ & 0.345 & 0.925 & 0.897 \\
\hline
\end{tabular}

Canonical correlation between $\boldsymbol{U}_{\mathrm{d} 2}$ and $\boldsymbol{V}_{\mathrm{d} 2}: 0.969$ 
of the degree of explanation should not be less than $30 \%$, in theory (Zhang, 2004), it might be perceived as more or less reluctantly accepted. When rainfall moves downstream, apart from the weaker degree of explanation of $\boldsymbol{Y}$ given by its set I of canonical variables $\boldsymbol{U}_{\mathrm{d} 1}$ and $\boldsymbol{V}_{\mathrm{d} 1}$, other degrees of explanation for canonical variables are generally acceptable.
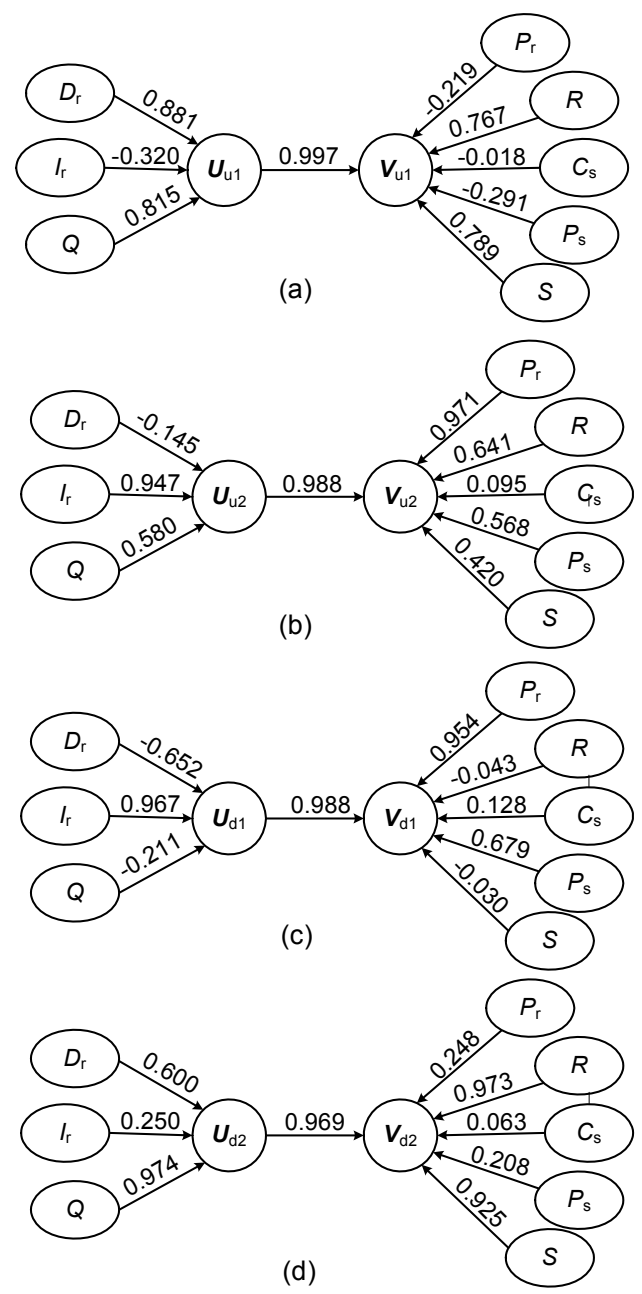

Fig. 2 Canonical loadings between the observed and canonical variables CVU I (a), CVU II (b), CVD I (c) and CVD II (d)

\section{Discussion}

Based on the CCA between the variables of rainfall and hydrologic response, it can be seen that, for both rainfall directions, the rainfall-runoff-erosion process in this study can be divided into an instantaneous and a cumulative response, of which the driving force is rainfall intensity and total rainfall, respectively, accompanied by splash erosion and wash erosion for each response.

When rainfall moves upstream, the canonical conversion coefficients of $R$ and $P_{\mathrm{r}}$ have opposite signs for the cumulative response (Eq. (5)), which means the slope response appears stronger with increasing $R$, while the decrease in $P_{\mathrm{r}}$, occurs mainly because $D_{\mathrm{r}}$ in the experiments with weak $I_{\mathrm{r}}$ is much longer than those with strong $I_{\mathrm{r}}$, which leads to the much larger $Q$ of the former. Moreover, $P_{\mathrm{r}}$ is mostly determined by rainfall intensity because the slope responses are already in steady state when $P_{\mathrm{r}}$ emerges (Ran et al., 2012b); hence, the larger the $Q$, the smaller the $I_{\mathrm{r}}$, leading to the weaker response of $P_{\mathrm{r}}$, just the opposite trend to the runoff response. When rainfall moves downstream, the canonical conversion coefficients of $R$ and $P_{\mathrm{r}}$ have the same sign, which means the slope hydrologic response appears stronger with increases of both $R$ and $P_{\mathrm{r}}$. Though under nearly the same initial conditions, the directions of rainfall and the overflow are the same along the slope while rainfall moves downstream. Consequently, a thin layer of sedimentary crust would form in the initial rainfall stages, due to initial overflow from the relatively high positions on the slope, resulting in evidently smaller permeability coefficient $\left(K_{\mathrm{s}}\right)$ and larger compaction of the surface soil than for the condition of upstream movement (Robinson and Woodun, 2008) together with the cumulative washing by overflow before peak runoff emerges. Thus, peak runoff appears larger than that for upstream movement experiments under similar conditions (Ran et al., 2012b).

Table 6 Redundancy analysis of CCA results in this study

\begin{tabular}{|c|c|c|c|c|}
\hline \multirow[t]{2}{*}{ Rainfall movement } & \multicolumn{2}{|c|}{$\begin{array}{l}\text { Proportion of variance of } \boldsymbol{X} \text { explained by } \\
\qquad \boldsymbol{U}_{\mathrm{u} 1}, \boldsymbol{U}_{\mathrm{u} 2}, \boldsymbol{U}_{\mathrm{d} 1}, \boldsymbol{U}_{\mathrm{d} 2}(\%)\end{array}$} & \multicolumn{2}{|c|}{$\begin{array}{l}\text { Proportion of variance of } \boldsymbol{X} \text { explained by } \\
\qquad \boldsymbol{V}_{\mathrm{u} 1}, \boldsymbol{V}_{\mathrm{u} 2}, \boldsymbol{V}_{\mathrm{d} 1}, \boldsymbol{V}_{\mathrm{d} 2}(\%)\end{array}$} \\
\hline & CVX1-1 & CVX1-2 & CVX2-1 & CVX2-2 \\
\hline Upstream-moving & 51.4 & 41.8 & 51.1 & 40.8 \\
\hline Downstream-moving & 46.9 & 45.7 & 45.7 & 43.0 \\
\hline \multirow[t]{2}{*}{ Rainfall movement } & \multicolumn{2}{|c|}{$\begin{array}{c}\text { Proportion of variance of } \boldsymbol{Y} \text { explained by } \\
\qquad V_{\mathrm{u} 1}, \boldsymbol{V}_{\mathrm{u} 2}, \boldsymbol{V}_{\mathrm{d} 1}, \boldsymbol{V}_{\mathrm{d} 2}(\%)\end{array}$} & \multicolumn{2}{|c|}{$\begin{array}{l}\text { Proportion of variance of } \boldsymbol{Y} \text { explained by } \\
\qquad \boldsymbol{U}_{\mathrm{u} 1}, \boldsymbol{U}_{\mathrm{u} 2}, \boldsymbol{U}_{\mathrm{d} 1}, \boldsymbol{U}_{\mathrm{d} 2}(\%)\end{array}$} \\
\hline & CVY1-1 & CVY1-2 & CVY2-1 & CVY2-2 \\
\hline Upstream-moving & 26.9 & 37.2 & 26.7 & 36.4 \\
\hline Downstream-moving & 27.8 & 38.2 & 27.2 & 35.9 \\
\hline
\end{tabular}


With the exception of the rectified variables of $\boldsymbol{V}_{\mathrm{u} 1}$ and $\boldsymbol{V}_{\mathrm{u} 2}$, it is shown both in the conversion formulas (Eqs. (5) and (8)) and canonical loading diagrams (Figs. 2a and 2d) that the degrees of erosion under conditions of the two rainfall directions are significantly different. In conditions of upstream movement, both $P_{\mathrm{s}}$ and $S$ have little impact on $\boldsymbol{V}_{\mathrm{u} 1}$ for their significantly smaller values of absolute conversion coefficients. However, when rainfall moves downstream, both $C_{\mathrm{s}}$ and $S$ (the erosion property variables) have a relatively large impact on $\boldsymbol{V}_{\mathrm{d} 2}$, because gaps between their canonical conversion coefficients, as well as canonical loadings and that of $R$, are a lot smaller than those in conditions of upstream movement. It was also found for $\boldsymbol{V}_{\mathrm{d} 2}$ that the degrees of influence of $P_{\mathrm{r}}, C_{\mathrm{s}}$, and $S$ are very close, the reason is that the erosive sediment on the slope surface could be relatively completely washed by overflow because the rainfall and overflow move in the same direction along the slope. When rainfall moves upstream, the change of surface permeability was less than that in downstream conditions (Ran et al., 2012b). In contrast, the erosive sediment could not be washed completely towards the outlet unless the washing duration was long enough, because the rainfall and overflow move in opposite directions along the slope (Ran et al., 2012a). On the whole, in response to the $Q$-dominated rainfall action, the erosion response is more strongly indicative of the whole hydrologic response characteristics for conditions of downstream rather than upstream movement.

In response to the force which is dominated by $I_{\mathrm{r}}$ (rainfall action), $P_{\mathrm{r}}$ appears to be the best determining factor of all the response characteristics, whether for conditions of upstream or downstream movement (Eqs. (6) and (7); Figs. 2b and 2c). Compared with the canonical loadings for $P_{\mathrm{r}}$ and $R$, both $C_{\mathrm{s}}$ and $P_{\mathrm{s}}$ have little impact on $\boldsymbol{V}_{\mathrm{u} 2}$ when rainfall moves upstream (Eq. (6), Fig. 2b). This was particularly so for $C_{\mathrm{s}}$, a cumulative variable, the response of which could be ignored, so are the variables $R$ and $S$ in $\boldsymbol{V}_{\mathrm{d} 1}$. Furthermore, both the canonical conversion coefficient and canonical loading of $P_{\mathrm{r}}$ are much larger than that for $P_{\mathrm{s}}$, because as each response is made, the surface hydrologic responses are mostly in a steady state, resulting in much smaller $K_{\mathrm{s}}$ (Ran et al., 2012b) and greater compaction of surface soil. Compared to the response at the beginning of each day, the majority of experiments appear to obviously increase in runoff levels, and have a decreased sediment discharge in this steady state (Table 1). As mentioned above, the erosive sediment may be left on the slope unless the washing time continues for a sufficient period, owing to the opposite directions of movement between rainfall and overflow. Thus, $P_{\mathrm{r}}$ has the strongest influence on the canonical variables of response properties, and $P_{\mathrm{s}}$ has a slightly weaker influence. For conditions of downstream movement, both the canonical loadings and conversion coefficient of $P_{\mathrm{s}}$ in $\boldsymbol{V}_{\mathrm{d} 1}$ are larger than those of $P_{\mathrm{r}}$ (Eq. (6)). Generally, the peak sediment discharge in downstream movement experiments has a larger impact on the canonical variable of response properties than conditions of upstream movement, of which reason is identical as the cumulative response mentioned above (Eqs. (5) and (8)).

Generally, for the dominant variables $\boldsymbol{U}_{\mathrm{d} 1}$ and $\boldsymbol{U}_{\mathrm{d} 2}$, absolutes for both canonical loadings and canonical conversion coefficients are much larger than those for other variables, showing the most distinctive divide between instantaneous and cumulative responses. The divide is, however, not so obvious in upstream movement experiments. This means that the analytics work of CCA for the conditions of downstream movement is more effective.

\section{Conclusions}

Based on the comparative rainfall-runoff experiments on a small-scale slope $(4 \mathrm{~m} \times 1 \mathrm{~m})$ under conditions of different rainfall movement directions along the slope surface, as well as the CCA between the rainfall and hydrologic response characteristics, it was found that the CCA method is valid for research into hydrologic responses to rainfall movement, and several conclusions were obtained via CCA.

1. Under both rainfall directions, the rainfall -runoff-erosion process in this study can be divided into instantaneous and cumulative responses, of which the driving force is rainfall intensity and total rainfall, respectively, accompanied by splash erosion and wash erosion for each response. Rainfall duration in this study did not have a dominant effect on the hydrologic response.

2. The response of $P_{\mathrm{r}}$ to the $I_{\mathrm{r}}$-dominated rainfall action appeared to be the most significant, both for conditions of upstream and downstream movement. The response of sediment erosion to rainfall appeared obviously weaker than that of runoff characteristics. The instantaneous responses of erosion in downstream 
conditions appear more strongly than those for upstream conditions. However, in reality, those responses may be more complex for various impact factors in nature, future studies will be carried out to further explore this subject.

3. The response of $R$ to the $Q$-dominated rainfall action appeared to be the most significant for conditions of both upstream and downstream movements. The cumulative responses of sediment erosion in downstream movement were also more significant than those for upstream movement.

4. The analytics work by CCA is more effective for the condition of downstream movement than upstream movement.

\section{References}

Arthur, E., Cornelis, W.M., Vermang, J., De Rocker, E., 2011. Effect of compost on erodibility of loamy sand under simulated rainfall. Catena, 85(1):67-72. [doi:10.1016/ j.catena.2010.12.005]

Assouline, S., Ben-Hur, M., 2006. Effects of rainfall intensity and slope gradient on the dynamics of interrill erosion during soil surface sealing. Catena, 66(3):211-220. [doi:10.1016/j.catena.2006.02.005]

Carmi, G., Berliner, P., 2008. The effect of soil crust on the generation of runoff on small plots in an arid environment Catena, 74(1):37-42. [doi:10.1016/j.catena.2008.02.002]

de Lima, J.L.M.P., Singh, V.P., 2003. Laboratory experiments on the influence of storm movement on overland flow. Physics and Chemistry of the Earth Parts $A / B / C, 28(6-7)$ : 277-282. [doi:10.1016/S1474-7065(03)00038-X]

de Lima, J.L.M.P., Tavares, P., Singh, V.P., de Lima, M.I.P., 2009. Investigating the nonlinear response of soil loss to storm direction using a circular soil flume. Geoderma, 152(1-2):9-15. [doi:10.1016/j.geoderma.2009.05.004]

Dessu, S.B., Melesse, A.M., 2012. Modelling the rainfallrunoff process of the Mara River basin using the Soil and Water Assessment Tool. Hydrological Processes, 26(26): 4038-4049. [doi:10.1002/hyp.9205]

Foster, G.R., Meyer, L.D., Onstad, C.A., 1977. An erosion equation derived from basic erosion principles. Transactions of the ASAE, 20(4):678-682.

He, Z.G., Tayfur, G., Ran, Q.H., Weng, H.X., 2013. Modeling pollutant transport in overland flow over non-planar and non-homogenous infiltrating surfaces. Journal of Zhejiang University-SCIENCE A (Applied Physics and Engineering), 14(2):110-119. [doi:10.1631/jzus.A1200231]

Montgomery, D.R., Dietrich, W.E., 2002. Runoff generation in a steep, soil-mantled landscape. Water Resources Research, 38(9):1168-1174. [doi:10.1029/2001WR000822]

Nunes, J.P., de Lima, J.L.M.P., Singh, V.P., de Lima, M.I.P., Vieira, G.N., 2006. Numerical modeling of surface runoff and erosion due to moving rainstorms at the drainage basin scale. Journal of Hydrology, 330(3-4):709-720. [doi:10.1016/j.jhydrol.2006.04.037]

Pappas, E.A., Huang, C.H., Bonta, J.V., 2011. Do upslope impervious surfaces impact the run-on/runoff relationship? Journal of Hydrologic Engineering, 16(4):345-350. [doi:10.1061/(ASCE)HE.1943-5584.0000325]

Ran, Q.H., Fu, Q., Su, D.Y., Zhao, J.J., Xu, Y.P., 2009. Impact of rainfall-movement direction on hillslope runoff generation. Journal of Zhejiang University (Engineering Science), 43(10):1915-1922 (in Chinese).

Ran, Q.H., Su, D.Y., Li, P., He, Z.G., 2011. Experimental study of the impact of rainfall characteristics on runoff generation and soil erosion. Journal of Hydrology, 424-425(6): 99-111. [doi:10.1016/j.jhydrol.2011.12.035]

Ran, Q.H., Shi, Z.N., Zhao, J.J., Xu, Y.P., 2012a. Impact of moving rainfall on soil erosion based on crust characteristics. Tsinghua Science and Technology, 52(6):821-829.

Ran, Q.H., Shi, Z.N., Fu, X.D., Wang, G.Q., Xu, Y.P., 2012 b. Impact of rainfall movement on soil crust development. International Journal of Sediment Research, 27(4): 439-450. [doi:10.1016/S1001-6279(13)60003-7]

Ran, Q.H., Su, D.Y., Qian, Q., Fu, X.D., Wang, G.Q., He, Z.G., 2012c. Physically-based approach to analyze rainfalltriggered landslide using hydraulic gradient as slide direction. Journal of Zhejiang University-SCIENCE A (Applied Physics and Engineering), 13(12):943-957. [doi:10.1631/jzus.A1200054]

Rice, R.M., 1972. Using canonical correlation for hydrological predictions. Hydrological Sciences Bulletin, 17(3):315321. [doi:10.1080/02626667209493837]

Robinson, D.A., Woodun, J.K., 2008. An experimental study of crust development on chalk downland soils and their impact on runoff and erosion. European Journal of Soil Science, 59(4):784-798. [doi:10.1111/j.1365-2389.2008. 01033.x]

Seo, Y., Schmidt, A.R., 2012. The effect of rainstorm movement on urban drainage network runoff hydrographs. Hydrological Processes, 26(25):3830-3841. [doi:10. 1002/hyp.8412]

Seo, Y., Schmidt, A.R., Sivapalan, M., 2012. Effect of storm movement on flood peaks: Analysis framework based on characteristic timescales. Water Resources Research, 48(5):1-12. [doi:10.1029/2011WR011761]

Singh, V.P., 2002. Effect of the duration and direction of storm movement on infiltrating planar flow with full areal coverage. Hydrological Processes, 16(7):1479-1511. [doi:10. 1002/hyp.358]

Singh, V.P., 2005. Effects of storm direction and duration on infiltrating planar flow with partial coverage. Hydrological Processes, 19(4):969-992. [doi:10.1002/hyp.5554]

Wang, W., Adali, T., Emge, D., 2012. Novel approach for target detection and classification using canonical correlation analysis. Journal of Signal Processing Systems, 68(3):379-390. [doi:10.1007/s11265-011-0625-7]

Wischmeier, W.H., Smith, D.D., 1978. Predicting Rainfall Erosion Losses: A Guide to Conservation Planning. US Department of Agriculture, Washington DC.

Yen, B.C., Chow, V.T., 1969. A laboratory study of surface runoff due to moving rainstorms. Water Resources Research, 5(5):989-1006. [doi:10.1029/WR005i005p00989]

Zhang, W.T., 2004. Advanced Statistic Analysis of SPSS. Higher Education Press, Beijing, China, p.286-287 (in Chinese). 